
SECAGEM POR ASPERSÃO (SPRAY DRYING)

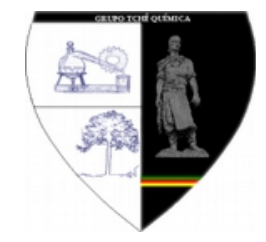

\title{
EVALUATION OF ANTIOXIDANT JUICE CASHEW (Anacardium occidentale Linn) IN Saccharomyces cerevisiae BEFORE AND AFTER DRYING SPRAY
}

\author{
GOMES, Débora Cássia Vieira ${ }^{1}$; COSTA, Dayane Alves ${ }^{1}$; ARAÚJO, Everton José Ferreira de ${ }^{1}$; \\ BATISTA, Paula do Nascimento ${ }^{1}$; ROCHA, Márcio dos Santos ${ }^{1}$; CAVALCANTE, Ana Amélia de \\ Carvalho Melo"; NUNES, Lívio Cesar Cunha ${ }^{1 *}$
}

\author{
${ }^{1}$ Programa de Pós-Graduação em Ciências Farmacêuticas da Universidade Federal do Piauí - UFPI / Núcleo \\ de Tecnologia Farmacêutica - NTF. Campus Universitário Ministro Petrônio Portela, s/n Ininga \\ CEP 64049-550, Teresina - PI, Brasil. (fone: +55 863215 5574) \\ ${ }^{*}$ Autor correspondente \\ e-mail: liviocesar@ufpi.com.br
}

Received 25 March 2013; accepted 29 March 2013

\begin{abstract}
RESUMO
Compostos classificados como antioxidantes atuam inibindo ou diminuindo os efeitos provocados pelos radicais livres. Vários métodos têm sido desenvolvidos para obter-se uma avaliação, seja qualitativa ou quantitativa, da capacidade antioxidante de inúmeros compostos, tanto através de testes químicos ou utilizando testes biológicos. Neste contexto, o presente trabalho objetivou avaliar a estabilidade do potencial antioxidante do suco e do material seco de caju (Anacardium ocidentale Linn) antes e após a técnica de spray- drying em leveduras Sacharomyces cerevisae proficientes e deficientes em defesas antioxidantes. $O$ suco de $A$. occidentale $L$ reduziu a inibição do crescimento em todas as linhagens testadas, demonstrando seu potencial antioxidante. Dentre todas as quatro linhagens da levedura, as variantes SOD2 $\Delta$ e SOD WT apresentaram maiores percentuais de redução da inibição do crescimento antes e após a secagem. Já nas mutantes SOD $1 \Delta / \mathrm{SOD} 2 \Delta$ e SOD $1 \Delta$ a substância testada apresentou baixa atividade antioxidante. O suco do pseudofruto de $A$. occidentale $L$ demonstrou potencial antioxidante, através do aumento da sobrevivência de leveduras, verificado pela diminuição do dano causado pelo peróxido de hidrogênio, antes e após a secagem por aspersão, o que mostra que a técnica de spray drying não alterou o potencial antioxidante do material analisado.
\end{abstract}

Palavras-chave: Caju, extrato seco, estabilidade, atomização

\begin{abstract}
Compounds classified as antioxidants act by inhibiting or reducing the effects caused by free radicals. Several methods have been developed to obtain an evaluation, it is qualitative or quantitative, the antioxidant capacity of various compounds, both by chemical tests or by using biological tests. In this context, this study aimed to evaluate the stability of the antioxidant potential of the juice and the dry material of cashew ((Anacardium ocidentale Linn) before and after spray-drying technique in yeast Saccharomyces cerevisiae proficient and deficient in antioxidant defenses. The juice of $A$. occidentale $\mathrm{L}$ reduced the growth inhibition in all strains of tested, demonstrating its antioxidant potential. Among all four strains of yeast, the variants SOD2 $\Delta$ WT and SOD showed higher percentages of reduction in growth inhibition before and after drying. Since the mutants SOD $1 \Delta /$ SOD2 $\Delta$ and SOD1 $\Delta$ the substance tested had low antioxidant activity. The juice of pseudofruit of $A$. occidentale $\mathrm{L}$ showed antioxidant potential by increasing the survival of yeast, verified in the reduction of damage caused by hydrogen peroxide, before and after spray drying, which shows that the technique of spray drying did not alter the antioxidant potential of the material analyzed.
\end{abstract}

Keywords: Cashew, dry extract, stability, atomization 


\section{INTRODUÇÃO}

Anacardium occidentale Linn (Família Anacardiaceae) é uma planta típica da região Nordeste do Brasil e cada vez mais o seu cultivo adquire importância socioeconômica. Botanicamente, o fruto verdadeiro do cajueiro é a castanha, uma amêndoa envolvida por uma casca dura; enquanto que o pedúnculo, pseudofruto ou maçã é conhecido como caju e apresenta estrutura semelhante a uma fruta, fibrosa e suculenta (LUBI e THACHIL, 2000).

O Caju possui considerável importância econômica, pois seus componentes têm numerosos usos comerciais. A sua castanha é de alto valor nutritivo, com cerca de $40-57 \%$ de óleo e $21 \%$ de proteínas. O cultivo do caju é uma das principais atividades agronômicas no Nordeste brasileiro, sendo que quase toda a produção está concentrada nos estados do Ceará, Piauí e Rio Grande do Norte. A castanha de caju e pedúnculo são utilizados na alimentação humana. O Brasil lidera a produção da maça do caju, detendo $95 \%$ da produção mundial. A composição do pedúnculo é muito complexa, apresentando vitaminas, taninos, sais minerais, ácidos orgânicos e carboidratos, o que o torna um alimento importante (FETUGA et al., 1975).

\section{Compostos} classificados

como antioxidantes atuam inibindo ou diminuindo os efeitos provocados pelos radicais livres. Vários métodos têm sido desenvolvidos para obter-se uma avaliação, seja qualitativa ou quantitativa, da capacidade antioxidante de inúmeros compostos, tanto através de testes químicos ou utilizando testes biológicos. Os testes químicos são bem mais rápidos e simples de serem executados. Entretanto, não possuem tanta correlação com as condições celulares do homem. Os ensaios microbianos 'in vivo' utilizando-se, especialmente, células eucarióticas de uma levedura conhecida como Saccharomyces cerevisiae, têm se mostrado muito inclinado na capacidade de avaliar a atividade antioxidante de diferentes compostos, fornecendo resultados rápidos, reprodutíveis e passíveis de serem correlacionados ao observado no homem (SOARES; ANDREAZZA; SALVADOR, 2005).

Por definição, spray-drying é o processo de transformação de soluções ou suspensões em partículas secas, formadas a partir da atomização de soluções ou suspensões em um meio aquecido. É um processo que ocorre de forma contínua, abrangendo as etapas de (1) alimentação da solução ou suspensão no atomizador, (2) atomização, (3) mistura do spray com o ar de secagem, (4) evaporação do solvente, (5) separação do produto seco (OAKLEY,1997).

Dentre as aplicações principais da secagem por aspersão, pode-se citar, na categoria de alimentos, a produção de leite em pó, café chá, ovos, cereal e condimentos. $\mathrm{Na}$ categoria farmacêutica, a produção de antibióticos, aditivos e ingredientes médicos, assim como o micro encapsulamento. $\mathrm{Na}$ categoria industrial, pode-se mencionar os pigmentos de tinta, materiais cerâmicos e suportes de catalisadores (DA SILVA, 2007).

Os antioxidantes naturais presentes em frutas e vegetais tornaram-se o objeto de maior interesse nos últimos anos. Tal importância é baseada em estudos farmacológicos, que demonstram a associação entre o consumo de produtos naturais e mais baixo risco de doenças (SINGH et al., 2008). Uma série de estudos têm relatado compostos fenólicos que têm excelente atividade antioxidante, atuando como doadores de hidrogênio, agentes redutores e varredores de radicais (RICE-EVANS, MILLER, \& PAGANGA, 1996). A inibição da acumulação de radicais livres é importante para reduzir o risco de doenças crônicas como doenças cardiovasculares e câncer (CAILLET et al, 2007; HWANG, YOON, E KANG, 2009).

Neste contexto, o presente trabalho objetivou avaliar a estabilidade do potencial antioxidante do suco e do material seco de A. ocidentale após a técnica de spray-drying em leveduras Sacharomyces cerevisae proficientes e deficientes em defesas antioxidantes.

\section{MATERIAL E MÉTODOS}

\subsection{Obtenção do suco}

O suco de $A$. ocidentale $L$. foi obtido a partir do pseudofruto da planta. O pseudofruto foi macerado para o processo de extração do suco, que foi utilizado em forma diluída em água 
destilada (1:10). Em seguida, o suco de caju foi filtrado em papel filtro.

\subsection{Resíduo seco}

Pesou-se $2 \mathrm{~g}$ do suco de caju em três diluições diferentes $(1: 10,1: 20,1: 30)$ em placas de Petri (06) previamente taradas, medindo, aproximadamente, $50 \mathrm{~mm}$ em diâmetro e $30 \mathrm{~mm}$ de altura. Evaporou o suco em banho-maria e deixou em estufa a $100-105^{\circ} \mathrm{C}$, por 3 horas. Deixou-se esfriar em dessecador, sobre pentóxido de fósforo e pesou-se as placas. O resíduo seco foi calculado em porcentagem sobre a massa.

\subsection{Técnica do Spray drying}

Primeiramente, verificou-se a válvula de saída do material (onde deve estar acoplado o recipiente para coleta do material). Após esta etapa, ligou-se o aparelho, acionando os botões relativos ao ventilador, ao compressor e à bomba e ajustou-se a temperatura de operação para um valor entre 170 e $190^{\circ} \mathrm{C}$, bem como se acionam as três resistências, sendo a terceira uma resistência termostática que tem como função manter a temperatura próxima do valor previamente ajustado. Para regulagem da pressão de atomização, fez uso de uma válvula posicionada na lateral do equipamento, ajustando-se a pressão desejada. Estando o equipamento operando adequadamente, deslocou-se a chave presente na bomba de mangas para a direita, de modo que ocorra fluxo ascendente da solução a ser processada, regulando-a para uma velocidade adequada de processamento. Como adjuvante, utilizou-se 12,9g de Aerosil ${ }^{\circledR} 200$ (Dióxido de Silício Coloidal) em $2000 \mathrm{~mL}$ de suco de caju. O processo durou cerca de 3 horas e o rendimento foi de $21,5 \mathrm{~g}$.

\subsection{Avaliação Antioxidante}

Para os ensaios de análise da atividade antioxidante, foram utilizadas linhagens proficientes e deficientes em sistema de defesa antioxidante (SOD WT, SOD1 $\Delta$, SOD2 $\Delta$, $\operatorname{SOD} 1 \Delta / \operatorname{SOD} 2 \Delta)$. A linhagem Sod1 é defectiva no sistema enzimático que envolve a enzima superóxido dismutase citoplasmática (CuZnSOD), enquanto a SOD2 o é na SOD mitocondrial (MnSOD); SOD1 $\Delta / \mathrm{SOD} 2 \Delta$ é o duplo mutante, defectivo tanto na Sod mitocondrial como na citoplasmática e SOD WT corresponde à linhagem selvagem, portanto proficiente nestas enzimas. Células em fase estacionária obtidas após a inoculação de uma colônia isolada em meio líquido YEL à temperatura de $30^{\circ} \mathrm{C}$ por 24 horas, sem agitação. Para a avaliação do potencial antioxidante, as linhagens foram estriadas em placa de YEPD contendo no centro um disco de papel filtro previamente estéreo em UV. Foram preparadas três placas, sendo que na placa 1 foi adicionado $100 \mu \mathrm{L}$ do suco de caju, na placa 2, adicionou-se $5 \mu \mathrm{L}$ de $\mathrm{H}_{2} \mathrm{O}_{2} 10 \mathrm{M}$, que correspondeu ao controle positivo e na placa 3 adicionou-se $100 \mu \mathrm{L}$ do suco do caju e $5 \mu \mathrm{L}$ de $\mathrm{H}_{2} \mathrm{O}_{2} 10 \mathrm{M}$ para o co-tratamento. A numeração das placas foi feita da seguinte forma: 1corresponde a SOD WT; 2- corresponde á SOD1 $\Delta$; 3- SOD2 $\Delta$; 4- SOD1 1 SOD2 $\Delta$ (FIGURA 1). As placas foram incubadas por $48 \mathrm{hs} \mathrm{em}$ estufa a $30^{\circ} \mathrm{C}$. Após esse período, mediu-se o halo de inibição do crescimento, sendo estes resultados tabelados e analisados e interpretados.

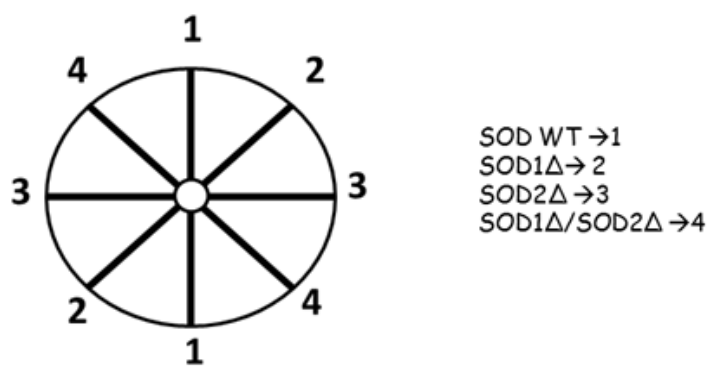

Figura 1. Disposição das linhagens nas placas utilizadas.

\section{RESULTADOS E DISCUSSÃO:}

Os antioxidantes atuam como defensores contra os radicais livres (RL) e espécies reativas de oxigênio (ERO). A produção destas espécies reativas é observada em diversas condições fisiológicas e desempenham papel fundamental no metabolismo. O estresse oxidativo resulta do desequilíbrio entre as espécies oxidativas e a 
defesa antioxidante, sendo o sistema oxidante predominante e responsável pelo estresse oxidativo (GUARIENTI; BERTOLIN; COSTA, 2010).

É bastante complicada a avaliação da capacidade antioxidante utilizando animais de laboratório e geralmente necessita de um grande número de animais para assegurar resultados estatisticamente significativos. Já nos ensaios realizados com microorganismos são muito mais fáceis, de rápida realização e podem utilizar um grande número de células com as mesmas características genéticas. Devido a essas características, a levedura Saccharomyces cerevisiae, um dos melhores modelos biológicos, são utilizadas para estudos de estresse oxidativo. Extensas razões tornam a levedura $S$. cerevisiae um exemplo de sistema eucariótico unicelular para estudos de estresse oxidativo. Trata-se de um organismo provido de núcleo e de organelas, onde o seu metabolismo é bastante semelhante ao de eucariotos superiores, com mecanismos próprios de ativação metabólica (citocromo P450) e de detoxificação, que não estão presentes em bactérias (SOARES; ANDREAZZA; SALVADOR, 2005).

Os resultados do resíduo seco encontrados em cada diluição estão apesentados no Quadro 1. Para o cálculo da quantidade de aerosil utilizado na técnica do spray drying utilizou-se a diluição 1:10, na qual tirou-se a média aritmética e obtendo um resultado de $12,9 \mathrm{~g}$ para $30 \%$ do aerosil.

Para o estudo utilizou-se diferentes linhagens de S. cerevisiae, que incluem: SOD1, SOD2, SOD1 $/ 2 \Delta$ (deficientes), SOD WT (proficiente) e, através do método de disco central observou-se a formação dos halos de inibição formados ao redor do disco.

A Tabela 1 mostra o resultado da inibição do crescimento medido em milímetros do suco de caju antes da realização da técnica de spray drying. Pode-se observar que na placa que utilizou-se no disco central apenas o suco de caju, não houve inibição do crescimento leveduriforme, mostrando que o caju não possui atividade oxidante. $\mathrm{Na}$ placa onde colocou-se apenas o agente estressor $\mathrm{H} 2 \mathrm{O} 2$ no disco central, houve inibição significativa do crescimento em todas as linhagens, comprovando que o $\mathrm{H} 2 \mathrm{O} 2$ age provocando um estresse oxidativo evidente. Na placa que foi colocado no disco central o suco de caju e o peróxido de hidrogênio, houve uma redução na inibição do crescimento mais evidente nas linhagens SOD WT e SOD 2 mutada, mostrando potencial antioxidante do suco para ambas as linhagens.

A Tabela 2 mostra que as placas contendo o suco de caju seco por aspersão apresentaram resultados similares à avaiação antioxidante antes da técnica de secagem, apresentando maior potencial antioxidante para as mesmas linhagens anteriores, SOD WT e SOD 2 mutada.

O suco de $A$. occidentale $L$ reduziu a inibição do crescimento em todas as linhagens de $S$. cerevisiae testadas, demonstrando seu potencial antioxidante, como apresentado nas Tabelas 1 e 2 . Dentre todas as quatro linhagens da levedura, as variantes SOD2 $\Delta$ e SOD WT apresentaram maiores percentuais de redução da inibição do crescimento antes e após a secagem. Já nas mutantes SOD1 $1 /$ SOD2 $\Delta$ e SOD1 $1 \Delta$ a substancia testada apresentou baixa atividade antioxidante.

Para proteger o organismo das ERO, as
células possuem enzimas de caráter antioxidante, tais como: Glutationa peroxidase (GPx), Catalase (CAT) e a Superóxido dismutase (SOD). A Saccharomyces cerevisiae, assim como muitos outros organimos eucariotos, possui CuZnSOD, um produto do gene SOD1, oriundo do citosol, núcleo e lisossomos. A MnSOD, que é um produto do gene SOD2, é natural da matriz mitocondrial (MARTINS; MANFREDINI; BENFATO, 2005).

A levedura Saccharomyces cerevisiae possui diversos mecanismos de defesa contra danos oxidativos ao DNA, dentre eles se encontram as enzimas superóxido dismutase, catalase e peroxidase além do próprio o reparo do DNA no mecanismo de replicação (LIMA; VIEIRA; COSTA JUNIOR, 2007). A enzima superóxido dismutase é a principal protetora celular frente a radicais livres, quando multada, como no caso da das linhagens utilizadas, expõe a células a danos no material genético.

As Figuras 2 e 3 mostram fotomicrografias do crescimento das leveduras nas três placas e em todas as linhagens estudadas antes e após a técnica de secagem 
por aspersão.

De acordo com Bilinski (apud GASPARRI, 2005) "as linhagens mutantes sod1 $1 \Delta$, que são deficientes nesta enzima, mostram problemas no crescimento em condições aeróbias, se apresentam muito sensíveis em situações de hiperóxia". As mutantes sod2 $\Delta$, possuem deficiência nesta enzima, são hipersensíveis a presença de oxigênio e crescem mal ou não crescem de forma alguma em fontes de carbono não fermentáveis (GASPARRI, 2005). A mais severamente afetadas, são as das linhagens $\operatorname{sod} 1 \Delta / \operatorname{sod} 2 \Delta$, deficientes em ambas as enzimas, que exibem peculiarmente todas as características das mutantes sod1 $\Delta$ e $\operatorname{sod} 2 \Delta$ (MARTINS; MANFREDINI; BENFATO, 2005).

O processo do Spray drying envolve basicamente cinco etapas: concentração, onde a matéria-prima normalmente é concentrada antes da introdução no aparelho; atomização; contato do líquido atomizado com gás quente; remoção da umidade e separação do produto final. o sistema tem a vantagem de poder ser projetado para qualquer volume de alimentação, empregando uma operação contínua, de fácil controle e aplicável tanto para substâncias termoestáveis como termolábeis. a partir disso, podem-se estabelecer parâmetros críticos de manuseio tais como a temperatura de admissão e de saída do ar, bem como do líquido utilizado, teor de sólidos, viscosidade, volatilidade, tensão superficial e até mesmo a resistência à abrasão e corrosão do material dos bicos de sucção (CHEGINI E GHOBADIAN, 2007). O ar dentro da câmara mantém um padrão de fluxo impedindo a deposição do produto seco na parede do atomizador, logo tanto o movimento do ar como a temperatura de entrada do ar influenciam o produto final. Entretanto o suco de algumas frutas tem propriedades naturais higroscópicas e termoplásticas o que consiste em um problema no manuseio do pó obtido por Spray drying, havendo a necessidade da utilização de um agente de secagem que pode ser amido, gomas naturais, maltodextrina ou sacarina, por exemplo, impedindo a coesão das partículas no interior do equipamento (VIVIANE et al., 2005).

O processo de secagem por aspersão possui diversas vantagens, como a seleção adequada do equipamento com base nas características pretendidas para o produto final; o controle da uniformidade e do tamanho das partículas do produto pela manipulação das variáveis do processo; o fato de ser um processo contínuo, podendo ser alteradas condições de operação sem a necessidade de interrupção; rapidez e rendimento, pois a evaporação ocorre em frações de segundos, em virtude da formação de inúmeras gotículas que proporcionam uma grande área superficial para trocas térmicas e transferência de massa; as partículas resultantes apresentam forma esférica uniforme e uma rápida dissolução, devido à grande área específica e o custo do processo são baixos (BAHANDARI et al. 1993).

As principais desvantagens deste processo de secagem são: o equipamento apresenta grandes dimensões, necessitando de instalações físicas adequadas; o custo inicial é alto, pois necessita de investimento em instalações e a limpeza dos equipamentos é onerosa, devido à utilização de grandes quantidades de fluidos de limpeza, como principalmente a água. Porém, o valor do produto final pode justificar o ônus inicial (BAHANDARI et al. 1993).

A facilidade e a rapidez na obtenção de culturas permitem sua manipulação em laboratório, para a realização dos mais diversos experimentos, podendo ser realizado um grande número de repetições, tornando essa levedura uma excelente fonte para estudos de estresse oxidativo (SOARES; ANDREAZZA; SALVADOR, 2005).

Sob o ponto de vista genético e metabólico, a levedura Saccharomyces cerevisiae, é um dos organismos mais categóricos à serem utilizados em testes biológicos, podendo ser realizada a avaliação da capacidade pela medida da sobrevivência de células tratadas com 0 antioxidante e agentes estressores (GUARIENTI; BERTOLIN; COSTA, 2010).

\section{CONCLUSÕES:}

O suco do pseudofruto de $A$. occidentale $L$ demonstrou potencial antioxidante, através do aumento da sobrevivência de leveduras, verificado pela diminuição do dano causado pelo peróxido de hidrogênio, antes e após a secagem por aspersão, o que mostra que a técnica de 
spray drying não alterou o potencial antioxidante do material analisado.

Sugere-se a realização de outros estudos sobre o concentrado de $A$. occidentale $L$ a fim de definir qual substância possui tal atividade antioxidante, para que este possa ser utilizado para fins terapêuticos.

\section{REFERÊNCIAS:}

1. Bahandari, B.R., A. Senoussi, E.D. Dumoulin And A. Albert. Drying Technol, 1993, 11: 1081-1092.

2. Caillet, S., Yu, H., Lessard, S., Lamoureux, G., Ajdukovic, D., \& Lacroix, M. Food Chemistry, 2007, 100, 542-552.

3. Chegini,G.R., Ghobadian, B. World Journal of Agricultural Sciences, 2007, 3 (2): 230-236.

4. Da Silva F.A.; Tese de doutorado, Universidade Federal do Rio Grande do Sul, Brasil, 2007.

5. Fetuga, B. L., Babatunde, G. M., Ekpenyong, T. B., \& Oyenuga, V. A. (1975).

The feeding stuff potential of cashew nut scraps kernel meal. In Proceedings of the conference of animal feed of tropical and sub-tropical origin (pp. 201-207). London: Tropical Products Institute.

6. Gasparri, S.; Dissertação de Mestrado, Universidade Luterana do Brasil , Brasil, 2005.

7. GUARIENTI, C., BERTOLIN, T. E., COSTA, J. A. V. Rev. Inst. Adolfo Lutz. São Paulo, 2010, v.69, n.1, p. 106-111.
8. Hwang, E. S., Yoon, G., \& Kang, H. T. Cellular and Molecular Life Sciences, 2009, 66, 2503-2524.

9. Lima, M. M. O.; Vieira, L. F.; Costa Júnior, J. S.. Avaliação da atividade antioxidante de Platonia insignis Mart.. (clusiaceae). 6 p. Disponível em:<http://www.redenet.edu.br/publicacoes/arquivos/2008 0922_085347_AGRO008.pdf>. Acesso em: 07 Janeiro 2012.

10. Lubi, M. C.; Thachil, E.T.. Designed Monomers and Polymers, 2000, v. 3, p. 123-153.

11. Martins, V., Manfredini, V., Benfato, M. S. Journal of Microbiology. Porto Alegre, 2005, v. 36, n. I, p. 347-351.

12. Oakley, D.E. Chemical engineering progress, 1997, p. 48-54.

13. Rice-Evans, C. A.; Miller, N. J.; Paganga, G. Free Radical Biology and Medicine, 1996., v. 20, p. 933-956,

14. Singh, M; Arseneault, M.; Sanderson, T. et al. J. Agric Food Chem., 2008, vol 56, n. 13,4885-4873.

15. Soares, D. G.; Andreazza, A. C.; Salvador, M.. Rev. Bras. Cienc. Farm., 2005, vol.41, n.1, p. 96.

16. Soares, D. G.; Andreazza, A. C.; Salvador, M.. Rev. Bras. Cienc. Farm. , 2005, vol.41, n.1, p. 96.

17. Viviane, S. Birchal, M. Laura Passos, Gloria, R.S. Wildhagen and A.S. Mujumdar. Drying Technol., 2005, 23: 611-637

PERIÓDICO TCHÊ QUÍMICA • www.periodico.tchequimica.com • Vol. 10 N. 19 • ISSN 1806-0374 (impresso) • ISSN 1806-9827 (CD-ROM) • ISSN 2179-0302 (meio eletrônico) 
Quadro 1. Resultados encontrados na metodologia do resíduo seco.

\begin{tabular}{|c|c|c|c|c|}
\hline Placa & Diluição & $\begin{array}{c}\text { Peso da Placa } \\
\mathbf{( g )}\end{array}$ & $\begin{array}{c}\text { Peso pós estufa } \\
\mathbf{( g )}\end{array}$ & $\begin{array}{c}\text { Resíduo Seco } \\
(\mathbf{g})\end{array}$ \\
\hline $\mathbf{1}$ & $1: 10$ & 52,117 & 52,161 & 0,044 \\
$\mathbf{2}$ & $1: 10$ & 46,251 & 46,293 & 0,042 \\
$\mathbf{3}$ & $1: 20$ & 34,337 & 34,355 & 0,018 \\
$\mathbf{4}$ & $1: 20$ & 31,955 & 31,974 & 0,019 \\
$\mathbf{5}$ & $1: 30$ & 27,515 & 27,527 & 0,012 \\
$\mathbf{6}$ & $1: 30$ & 30,718 & 30,733 & 0,015 \\
\hline
\end{tabular}

Tabela 1: Inibição do crescimento em milímetros do suco de caju antes da técnica de spray drying

\begin{tabular}{|c|c|c|c|c|}
\hline & SOD WT & SOD $1 \triangle$ & $S O D 2 \Delta$ & $\begin{array}{l}\text { SOD } 1 \Delta \\
\text { /SOD } 2 \Delta\end{array}$ \\
\hline Caju & $0 \mathrm{~mm}$ & $0 \mathrm{~mm}$ & $0 \mathrm{~mm}$ & $0 \mathrm{~mm}$ \\
\hline Caju + $\mathrm{H}_{2} \mathrm{O} 2$ & $10 \mathrm{~mm}$ & $10 \mathrm{~mm}$ & $11,5 \mathrm{~mm}$ & $15 \mathrm{~mm}$ \\
\hline $\mathrm{H} 2 \mathrm{O} 2$ & $14,5 \mathrm{~mm}$ & $10,5 \mathrm{~mm}$ & $18,5 \mathrm{~mm}$ & $15,5 \mathrm{~mm}$ \\
\hline
\end{tabular}

Tabela 2: Inibição do crescimento em milímetros do suco do caju após a técnica de spray drying

\begin{tabular}{|c|c|c|c|c|}
\hline & SOD WT & SOD $1 \Delta$ & SOD $2 \triangle$ & $\begin{array}{l}\text { SOD } 1 \Delta \\
\text { /SOD } 2 \Delta\end{array}$ \\
\hline Caju & $0 \mathrm{~mm}$ & $0 \mathrm{~mm}$ & $0 \mathrm{~mm}$ & $0 \mathrm{~mm}$ \\
\hline Caju + H2O2 & $13 \mathrm{~mm}$ & $10.5 \mathrm{~mm}$ & $12,5 \mathrm{~mm}$ & $13 \mathrm{~mm}$ \\
\hline $\mathrm{H} 2 \mathrm{O} 2$ & $15 \mathrm{~mm}$ & $11 \mathrm{~mm}$ & $16 \mathrm{~mm}$ & $14 \mathrm{~mm}$ \\
\hline
\end{tabular}




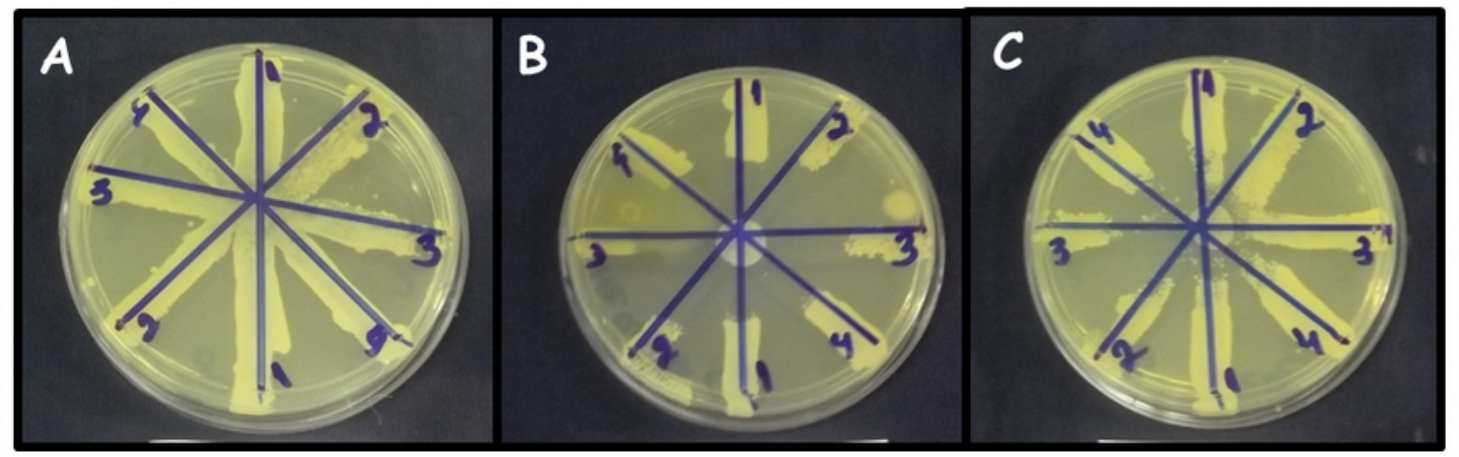

Figura 2. Resultados da avaliação antioxidante antes da técnica de spray drying. A- Suco de caju; B-Peróxido de Hidrogênio; C - Suco + peróxido.

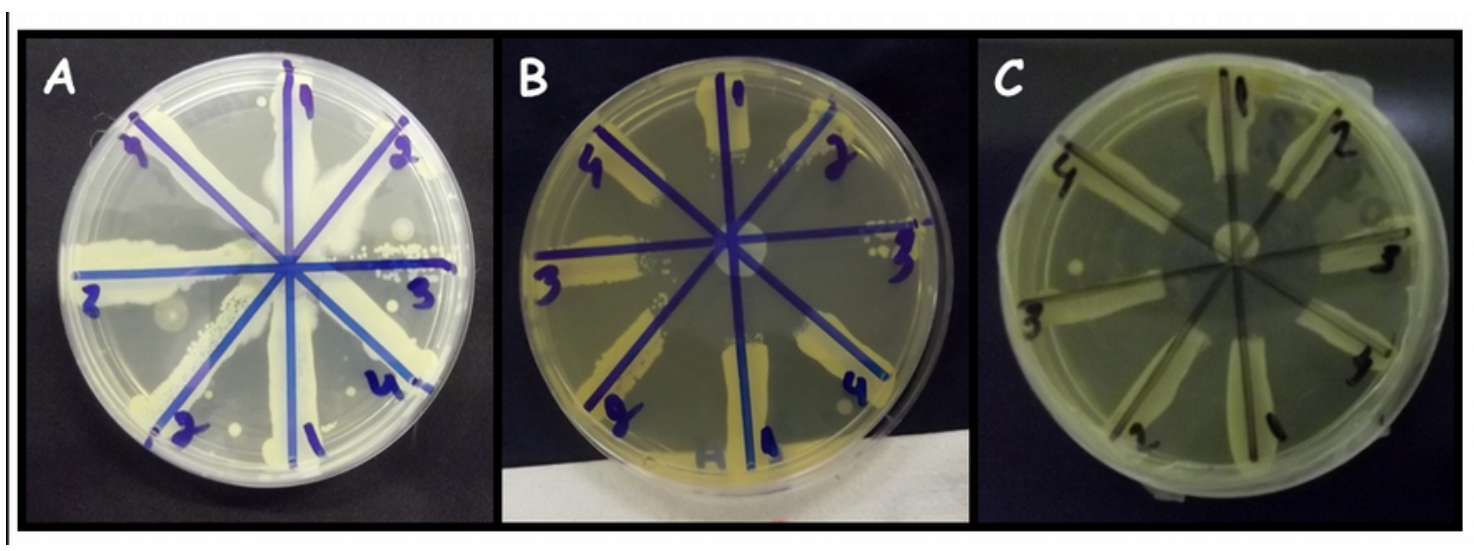

Figura 3. Resultados da avaliação antioxidante após a técnica de spray drying. A- Suco de caju; B- Peróxido de Hidrogênio; C - Suco + peróxido.

PERIÓDICO TCHÊ QUÍMICA • www.periodico.tchequimica.com • Vol. 10 N. 19. - ISSN 1806-0374 (impresso) • ISSN 1806-9827 (CD-ROM) • ISSN 2179-0302 (meio eletrônico)

\author{
(C) 2011. Porto Alegre, RS. Brasil
}

The Periódico Tchê Química (ISSN: 1806-0374; 2179-0302) is an open-access journal since 2004. Journal DOI: 10.52571/PTQ. http://www.tchequimica.com. This text was introduced in this file in 2021 for compliance reasons.

๑ The Author(s)

OPEN ACCESS. This article is licensed under a Creative Commons Attribution 4.0 (CC BY 4.0) International License, which permits use, sharing, adaptation, distribution, and reproduction in any medium or format, as long as you give appropriate credit to the original author(s) and he source, provide a link to the Creative Commons license, and indicate if changes were made. The images or other third-party material in this article are included in the or exceeds the permitted use, you will need to obtain permission directly from the copyright holder. To view a copy of this license, visit http//creativecommons. orgllicenses/by/4.0/. 